\title{
Sex-based differences in the prevalence of acute mountain sickness: a meta-analysis
}

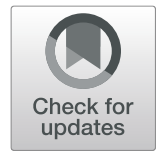

Yun-Peng Hou, Jia-Lin Wu, Chao Tan, Yu Chen, Rui Guo and Yong-Jun Luo*

\begin{abstract}
Background: When lowlanders rapidly ascend to altitudes $>2500 \mathrm{~m}$, they may develop acute mountain sickness (AMS). The individual susceptibility, ascending velocity, time spent at altitude, activity levels and altitude reached are considered risk factors for AMS. However, it is not clear whether sex is a risk factor. The results have been inconclusive. We conducted a meta-analysis to test whether there were sex-based differences in the prevalence of AMS using Lake Louise Scoring System.

Methods: Systematic searches were performed in August 2019 in EMBASE, PubMed, and Web of Science for prospective studies with AMS data for men and women. The titles and abstracts were independently checked in the primary screening step, and the selected full-text articles were independently assessed in the secondary screening step by the two authors (YPH and JLW) based on pre-defined inclusion criteria. The meta-analysis was performed using by the STATA 14.1 software program. A random-effects model was employed.

Results: Eighteen eligible prospective studies were included. A total of 7669 participants (2639 [34.4\%] women) were tested. The results showed that there was a statistically significant higher prevalence rate of AMS in women than in men $(R R=1.24,95 \% \mathrm{Cl} 1.09-1.41)$, regardless of age or race. Howerver, the heterogeneity was significant in the analysis $\left(\operatorname{Tau}^{2}=\right.$ $0.0403, \mathrm{Ch}^{2}=50.15, d f=17 ; P^{2}=66.1 \%, P=0.000$ ), it was main caused by different numbers of subjects among the studies (coefficient $=-2.17, P=0.049$ ). Besides, the results showed that there was no evidence of significant publication bias in the combined studies on the basis of Egger's test (bias coefficient $=1.48, P=0.052)$ and Begg's test $(P=0.130)$.

Conclusions: According to this study, the statistically significant finding emerging from this study was that women have a higher prevalence of AMS. However, the authors could not exclude studies where patients were on acetazolamide. Our analysis provided a direction for future studies of the relationship of sex and the risk of AMS, such as the pathological mechanism and prevention research.
\end{abstract}

Keywords: Prevalence, Sex differences, Acute mountain sickness, Risk factors

\section{Background}

Acute mountain sickness (AMS) may occur when a person who is used to being at a low altitude ascends to a higher altitude [1]. The typical symptoms include headache, anorexia, nausea, vomiting, dyspnoea, lassitude, and insomnia after arriving at a high altitude. This condition is termed AMS. It is a clinical syndrome in which the body decompensates in response to acute hypoxic conditions [2-4]; AMS is exacerbated by exercise and can be disabling [5]. More seriously, if symptoms are ignored, AMS can develop into life-threatening high-altitude cerebral

\footnotetext{
* Correspondence: 333333@163.com

Department of Military Medical Geography, Army Medical Service Training Base, Army Medical University, Chongqing 400038, China
}

edema [6]. The individual susceptibility, ascending velocity, time spent at altitude, activity levels and altitude reached may be the common causes of AMS [7]; men and women present with different AMS morbidity profiles. Previous studies that reported sex as a risk factor for AMS were inconsistent, although some indicated that women are more likely to suffer from AMS than men. For example, in Murdoch's report, the prevalence of AMS was $88.6 \%$ vs $69.0 \%$ (women vs. men, respectively) [4], and rates of $60.0 \%$ vs. $21.9 \%$ (women vs. men, respectively) were reported in the study by other authors [8], while other studies showed a higher prevalence in men $[9,10]$ or no sex-based difference $[11,12]$. Although it has been suggested that sex-based differences in the prevalence

(c) The Author(s). 2019 Open Access This article is distributed under the terms of the Creative Commons Attribution 4.0 International License (http://creativecommons.org/licenses/by/4.0/), which permits unrestricted use, distribution, and 
of AMS patients exist, to date, no systematic review or meta-analysis has addressed this issue.

The perspective in the existing literature is that the differences between men and women are mainly determined by the physical differences and the different hormone levels $[13,14]$. Some investigators believe that the differences in the prevalence of AMS between men and women is also affected by hormones or other factors associated with hormones [15]. However, that is only hypothesis, and the pathophysiological mechanism of AMS is still not entirely clear. To determine whether there are sex-based differences in the prevalence of AMS, we conducted a systematic literature review of studies using the same criteria and performed a meta-analysis to quantify the results.

\section{Methods}

This review was conducted according to the PRISMA (Preferred Reporting Items for Systematic Reviews and Meta-analyses) guidelines [16].

\section{Search strategy}

Searches were conducted in PubMed, EMBASE and Web of Science for articles published before August 2019. The search strings included terms pertaining to: 1) AMS (such as, acute mountain sickness, acute high altitude disease, acute mountain illness, altitude disease, Lake Louise Scoring System (LLSS)); 2) epidemiological indicators of disease (such as, prevalence, incidence, risk, epidemiology); and 3) subjects characteristics (such as, sex, gender), using the logical connectives "OR" and "AND" to combine them. The titles and abstracts of the returned articles were searched for the relevant variables, and the initial eliminations were made. The publication dates were limited to article published after 1991 because the LLSS was first propounded in February, 1991 [17]. The language was restricted to English. Furthermore, the studies listed in the references of the articles were reviewed.

\section{Study selection}

Two authors, YPH and JLW, independently reviewed the publications. We first applied Endnote X9 software to eliminate duplicate publications, and read the titles and abstracts to initially select candidate articles. For those publications that were not clearly described, we screened them by downloading and reading the full texts, and discrepancies were resolved by consensus. The eligible studies met the following criteria:

1) The studies were limited to prospective studies with high reliability and sufficient data. Clinical research, interventional experiments or retrospective studies were excluded due to the possibility of selection bias.

2) In terms of the diagnostic criteria, the included studies adopted the same data collection technology, used the LLSS [17], and applied the same two cut-off values (LLSS $\geq 3$ or $\geq 4$ ) to define AMS. Studies using other diagnostic criteria were excluded from the pooled analysis because diverse criteria may result in different prevalence, affecting the sex-based differences.

3) The studies included sex-specific numbers or rates, or the data needed to calculate the same, i.e., the prevalence or percentages of men and women with AMS.

4) The average age of the subjects was over 18 years, as younger subjects are not sufficiently physically mature to enable the assessment of sex-based effects.

5) The minimum altitude was $2500 \mathrm{~m}$. This height can cause physical changes, such as acute altitude sickness, high altitude pulmonary edema and other diseases.

\section{Data extraction}

The data extraction table was developed by YPH and JLW. Disagreements were reconciled through consensus in face-to-face meetings, and consensus was reached after discussion.

The information extracted from each study included the first author, publication year, location, average age, race, participant type, altitude, cut-off value for the LLSS to identify AMS, and number of women or men with AMS or the AMS prevalence rates.

\section{Assessment of AMS}

The methods for the assessment of AMS include the LLSS, the Environmental Symptoms Questionnaire III (ESQ-III) and so on $[18,19]$. All of these methods are widely utilized in studies of the effects of altitude, but there is still no golden standard and the methods for the assessment of AMS depend on subjective symptoms. Some articles have compared the LLSS with the ESQ-III AMS score, subjects are likely to receive a different AMS diagnosis when evaluated by different scoring systems [20,21]. Despite that, this meta-analysis was performed based on the LLSS. This criterion aimed to reduce the confounding factors introduced by means of different evaluation methods and improve the quality of the assessment. Scores in the LLSS range from 0 to 12, and a total score $\geq 3$ in the presence of a headache was the diagnostic criterion for AMS. However, some researchers used 4 points as a cut-off value to diagnose AMS [22, 23]. We therefore concluded that a subgroup analysis was needed to evaluate the implications of the different cut-off values.

\section{Quality assessment}

The methodological quality of each study using LLSS as assessed based on the tool developed by Loney et al. [24], which aimed to critically appraise research articles that estimate the prevalence or incidence of a disease. Two authors (YPH and JLW) independently implemented this method, with all disagreements resolved by consensus. The scoring system is an 8-point scale consisting of three parts: validity of research methods (0-6 points), 
interpretation of the results ( $0-1$ point) and applicability of the results (0-1 point). Detailed scores for each study can be found in Appendix. A total score of 4 or 5 is considered adequate quality, and a score $\geq 6$ points is defined as high quality. However, for publications with a score $\leq 3$ were excluded to ensure that the included studies had adequate reliability and methodological quality.

\section{Statistical analysis}

The meta-analysis was performed using Stata 14.1 (Stata Corp, College Station, TX, USA). We used a randomeffects model to aggregate the data because the randomeffects model is more conservative than the fixed-effect model; in addition, it allows for the existence of heterogeneity. Relative risks $(R R)$ were used to assess the binary outcomes variables rather than odds ratios $(O R)$, as the $R R$ are easier to explain and do not overestimate the magnitude of the effect [25]. Heterogeneity among studies was tested using the I2 statistic. Meta-regression analysis and subgroup analysis were used to verify the source of the heterogeneity. Egger's test, Begg's test and meta-funnel plot asymmetry were used to test for the presence of publication bias [26]. There is a significant difference if $P<0.05$.

\section{Results}

\section{Search results}

A total of 1718 publications relevant to AMS were identified in the databases. Additionally, 4 additional records were identified through other sources. The abstracts of 974 were reviewed, of which 80 articles were reviewed in full, and 18 were ultimately included. The excluded studies were thirty-one with no sex-based data reported or specific numbers, eight that were not in English, six that were not prospective studies, fourteen with no sex differences, nine with average ages $<18$ years, two without fulltext versions available and one without a response from the authors regarding requested data. Therefore, a total of 18 full-text articles were included in this meta-analysis (Table 1), and the selection flow chart is shown in Fig. 1.

\section{Selected studies and characteristics}

A total of 18 studies [4, 8-12, 22, 23, 27-36] on AMS using LLSS were included in this analysis, and the detailed information is shown in Table 1. The publication period ranged from 1995 to 2018, with the majority of the publication dates being after 2000. The experimental subjects included guests, pilgrims, hikers, volunteers, and mountaineers. The study altitudes ranged from $2200 \mathrm{~m}$ to $5400 \mathrm{~m}$, but the altitude in most studies was above $2500 \mathrm{~m}$. The number of subjects was between 47 and 1932, and the total number included in the analysis was 7669. The highest overall prevalence of AMS was $77.9 \%$, and the lowest was $16.6 \%$ [4, 22]. The maximal single-study prevalence rates for AMS in women and men were 88.6 and $69.0 \%$, respectively, whereas the minimal values in women and men were 14.3 and $15.8 \%$, respectively $[4,22,32]$. Fifteen studies reported that women had a higher prevalence of AMS than men in the same experiment. It should be noted that all of the studies used the LLSS for the diagnosis of AMS, but 4 of them defined the diagnostic criterion as an LLSS value of at least 4 with headache present, whereas the remaining 15 studies defined the criterion as an LLSS score of at least 3 with headache present. In selecting the studies, some studies were excluded on the basis of ambiguous data regarding the number of subjects or the prevalence despite demonstrating a sex-based distinction [37].

\section{Quality assessment}

The details of the quality assessment of the included studies are listed in Appendix; 4 studies were rated "high quality" (22.2\%, total score $\geq 6)$, 14 studies were considered "good quality" ( $77.8 \%$; total score $=4$ to 5 ), and there was one thesis rated "low quality" (total score $\leq 3$ ). The limitations affecting the quality of the studies were generally the following: small sample size (10 of 18 studies), refusal to participate not described (16 of 18 studies), biased assessors (17 of 18 studies) and 95\% confidence intervals not provided (13 of 18 studies). To ensure the reliability of the included studies, we excluded low-quality studies, and 18 studies were included in the final meta-analysis.

\section{Meta-analysis results of sex-based difference in AMS}

We selected a fixed-effects model for the initial stage of the analysis, but the heterogeneity did not meet the condition for this model $\left(\mathrm{Tau}^{2}=0.0403, \mathrm{Chi}^{2}=50.15, d f=\right.$ $\left.17 ; I^{2}=66.1 \%, P=0.000\right)$. We therefore chose a randomeffects model for the final evaluation of the data. The results showed that there was a statistically significant higher prevalence of AMS in women than in men $(R R=$ $1.24,95 \%$ CI $1.09-1.41$ ). The $R R$ values for the individual studies and the pooled estimate are shown in Fig. 2.

\section{Meta-regression analysis}

The heterogeneity was significant in the analysis $\left(I^{2}=\right.$ $66.1 \%, P=0.000$ ), so we performed the meta-regression analysis to explore the contribution of the four covariates (race, age, LLSS cut-off value and number of subjects) in the heterogeneity. The results indicated that the number of subjects was a possible contributor to the heterogeneity (coefficient $=-2.17, P=0.049$ ). The contributions of race, LLSS cut-off value and age were not obvious $(P=0.826$, $P=0.901, P=0.970$, respectively, Table 2).

\section{Subgroup analysis}

The result of the regression analysis showed that different numbers of subjects $(n<300$ vs. $n \geq 300)$ was the main cause of the heterogeneity, and the heterogeneity was improved after the subgroup analysis $\left(I^{2}=24.6 \%, P=0.225\right)$. The 
Table 1 Details of eligible AMS-related studies that were included in the meta-analysis

\begin{tabular}{|c|c|c|c|c|c|c|c|c|c|c|}
\hline \multirow[t]{2}{*}{ References } & \multirow[t]{2}{*}{ Location } & \multirow{2}{*}{$\begin{array}{l}\text { Race of } \\
\text { subjects }\end{array}$} & \multirow[t]{2}{*}{ Subjects } & \multirow{2}{*}{$\begin{array}{l}\text { Diagnostic } \\
\text { criteria }\end{array}$} & \multirow{2}{*}{$\begin{array}{l}\text { Average } \\
\text { age (years) }\end{array}$} & \multirow{2}{*}{$\begin{array}{l}\text { Altitude } \\
(\mathrm{m})\end{array}$} & \multirow{2}{*}{$\begin{array}{l}\text { Total } \\
\text { subjects }(n)\end{array}$} & \multicolumn{3}{|c|}{ Prevalence (\%) } \\
\hline & & & & & & & & Total & Women & Men \\
\hline Murdoch et al. (1995) [4] & $\begin{array}{l}\text { Shyangboche, } \\
\text { Asia }\end{array}$ & Asian & Guests & LLSS $\geq 3$ & 45.3 & 3740 & 154 & $\begin{array}{l}77.9 \\
(120 / \\
154)\end{array}$ & $\begin{array}{l}88.6 \\
(62 / 70)\end{array}$ & $\begin{array}{l}69.0 \\
(58 / 84)\end{array}$ \\
\hline Ziaee et al. (2003) [9] & $\begin{array}{l}\text { Mount } \\
\text { Damavand, } \\
\text { Asia }\end{array}$ & Asian & Hikers & LLSS $\geq 3$ & 31.9 & 4200 & 459 & $\begin{array}{l}60.8 \\
(279 / \\
459)\end{array}$ & $\begin{array}{l}58.1 \\
(86 / \\
148)\end{array}$ & $\begin{array}{l}63.1 \\
(196 / \\
311)\end{array}$ \\
\hline Wagner et al. (2008) [10] & $\begin{array}{l}\text { Mt. Whitney, } \\
\text { North America }\end{array}$ & American & Hikers & LLSS $\geq 3$ & 37.6 & 4419 & 886 & $\begin{array}{l}42.6 \\
(337 / \\
886)\end{array}$ & $\begin{array}{l}37.7 \\
(80 / \\
212)\end{array}$ & $\begin{array}{l}44.1 \\
(297 / \\
674)\end{array}$ \\
\hline Jafarian et al. (2008) [27] & Tehran, Asia & Asian & Volunteers & $L L S S \geq 3$ & 28.8 & 3450 & 90 & $\begin{array}{l}37.8 \\
(34 / 90)\end{array}$ & $\begin{array}{l}53.3 \\
(16 / 30)\end{array}$ & $\begin{array}{l}30.0 \\
(18 / 60)\end{array}$ \\
\hline Mairer et al. (2009) [22] & $\begin{array}{l}\text { Austrian Alps, } \\
\text { Europe }\end{array}$ & European & Hikers & $L L S S \geq 4$ & 37.4 & $2200-3500$ & 422 & $\begin{array}{l}16.6 \\
(70 / \\
422)\end{array}$ & $\begin{array}{l}18.9 \\
(20 / \\
106)\end{array}$ & $\begin{array}{l}15.8 \\
(50 / \\
316)\end{array}$ \\
\hline Wu et al. (2010) [28] & Lhasa, Asia & Asian & Passengers & LLSS $\geq 3$ & 40.4 & $2600-5072$ & 222 & $\begin{array}{l}27.0 \\
(60 / \\
222)\end{array}$ & $\begin{array}{l}34.5 \\
(30 / 87)\end{array}$ & $\begin{array}{l}22.2 \\
(30 / \\
135)\end{array}$ \\
\hline Wang et al. (2010) [11] & $\begin{array}{l}\text { Jade } \\
\text { Mountain, Asia }\end{array}$ & Asian & Hikers & LLSS $\geq 3$ & 40.2 & 3925 & 1066 & $\begin{array}{l}36.0 \\
(384 / \\
1066)\end{array}$ & $\begin{array}{l}36.3 \\
(128 / \\
353)\end{array}$ & $\begin{array}{l}35.9 \\
(256 / \\
713)\end{array}$ \\
\hline Mairer et al. (2010) [29] & Alps, Europe & European & Mountaineers & LLSS $\geq 4$ & $\begin{array}{l}\text { 34.7(group } \\
\text { 1) } \\
\text { 36.8(group } \\
\text { 2) }\end{array}$ & $\begin{array}{l}3454 \text { and } \\
3817\end{array}$ & 155 & $\begin{array}{l}37.4 \\
(58 / \\
155)\end{array}$ & $\begin{array}{l}39.3 \\
(11 / 28)\end{array}$ & $\begin{array}{l}37.0 \\
(47 / \\
127)\end{array}$ \\
\hline Modesti et al. (2011) [8] & $\begin{array}{l}\text { Mount Everest } \\
\text { Base Camp, } \\
\text { Asia }\end{array}$ & Asian & Volunteers & LLSS $\geq 4$ & 40 & 5400 & 47 & $\begin{array}{l}34.0 \\
(16 / 47)\end{array}$ & $\begin{array}{l}60.0(9 / \\
15)\end{array}$ & $\begin{array}{l}21.9(7 / \\
32)\end{array}$ \\
\hline Chen et al. (2012) [23] & $\begin{array}{l}\text { Jade } \\
\text { Mountain, Asia }\end{array}$ & Asian & Hikers & LLSS $\geq 4$ & 42 & $3402-3952$ & 787 & $\begin{array}{l}32.8 \\
(258 / \\
787)\end{array}$ & $\begin{array}{l}34.7 \\
(92 / \\
265)\end{array}$ & $\begin{array}{l}31.8 \\
(166 / \\
522)\end{array}$ \\
\hline Maclnnis et al. (2013) [30] & $\begin{array}{l}\text { Gosainkunda, } \\
\text { Asia }\end{array}$ & Asian & Pilgrims & LLSS $\geq 3$ & 36.7 & 4380 & 491 & $\begin{array}{l}34.0 \\
(167 / \\
491)\end{array}$ & $\begin{array}{l}45.5 \\
(67 / \\
147)\end{array}$ & $\begin{array}{l}29.1 \\
(100 / \\
344)\end{array}$ \\
\hline Mandolesi et al. (2014) [31] & $\begin{array}{l}\text { Mount Rosa, } \\
\text { Europe }\end{array}$ & European & Mountaineers & LLSS $\geq 3$ & 36.4 & $3647-4559$ & 60 & $\begin{array}{l}40.0 \\
(24 / 60)\end{array}$ & $\begin{array}{l}54.5(6 / \\
11)\end{array}$ & $\begin{array}{l}36.7 \\
(18 / 49)\end{array}$ \\
\hline Hsu et al. (2015) [32] & $\begin{array}{l}\text { Jiaming Lake, } \\
\text { Asia }\end{array}$ & Asian & Mountaineers & LLSS $\geq 3$ & 19.8 & 3550 & 91 & $\begin{array}{l}20.9 \\
(19 / 91)\end{array}$ & $\begin{array}{l}14.3(4 / \\
28)\end{array}$ & $\begin{array}{l}23.8 \\
(15 / 63)\end{array}$ \\
\hline Ren et al.(2015) [33] & Lhasa, Asia & Asian & Volunteers & LLSS $\geq 4$ & 38.4 & $3100-4300$ & 80 & $\begin{array}{l}43.8 \\
(35 / 80)\end{array}$ & $\begin{array}{l}53.1 \\
(26 / 49)\end{array}$ & $\begin{array}{l}29.0(9 / \\
31)\end{array}$ \\
\hline Horiuchi et al. (2016) [34] & $\begin{array}{l}\text { Mount Fuji, } \\
\text { Asia }\end{array}$ & Asian & Climbers & LLSS $\geq 3$ & 36.1 & 3776 & 345 & $\begin{array}{l}29.5 \\
(98 / \\
345)\end{array}$ & $\begin{array}{l}32.6 \\
(46 / \\
141)\end{array}$ & $\begin{array}{l}25.5 \\
(52 / \\
204)\end{array}$ \\
\hline $\begin{array}{l}\text { Sánchez-Mascuñano et al. } \\
\text { (2017) [35] }\end{array}$ & Spain, Europe & European & Travellers & LLSS $\geq 3$ & 37.7 & $>3400$ & 302 & $\begin{array}{l}25.8 \\
(78 / \\
302)\end{array}$ & $\begin{array}{l}39.0 \\
(53 / \\
156)\end{array}$ & $\begin{array}{l}17.1 \\
(25 / \\
146)\end{array}$ \\
\hline Horiuchi et al. (2018) [12] & $\begin{array}{l}\text { Mount Fuji, } \\
\text { Asia }\end{array}$ & Asian & Climbers & LLSS $\geq 3$ & 37.4 & $>2870$ & 1932 & $\begin{array}{l}31.6 \\
(610 / \\
1932)\end{array}$ & $\begin{array}{l}32.9 \\
(252 / \\
767)\end{array}$ & $\begin{array}{l}30.7 \\
(358 / \\
1165)\end{array}$ \\
\hline J. Boos et al. (2018) [36] & Himalayas,Asia & Asian & $\begin{array}{l}\text { Military } \\
\text { servicemen }\end{array}$ & LLSS $\geq 3$ & 32.1 & 5140 & 80 & $\begin{array}{l}47.5 \\
(38 / 80)\end{array}$ & $\begin{array}{l}69.2 \\
(18 / 26)\end{array}$ & $\begin{array}{l}37.0 \% \\
(20 / 54)\end{array}$ \\
\hline
\end{tabular}

AMS acute mountain sickness, LLSS Lake Louise Scoring System

evaluation of the effect of the number of subjects showed that the studies with small sample sizes had a higher rate of AMS $(R R=1.60,95 \%$ CI 1.27-2.00) compared with those that with larger sample sizes $(R R=1.12,95 \%$ CI $0.98-1.28)$.
Three other subgroups (race, age, LLSS cut-off value) were analyzed in the context of the overall estimate by means of different stratifications. Subgroup analyses were performed to determine whether sex-based differences emerged in 


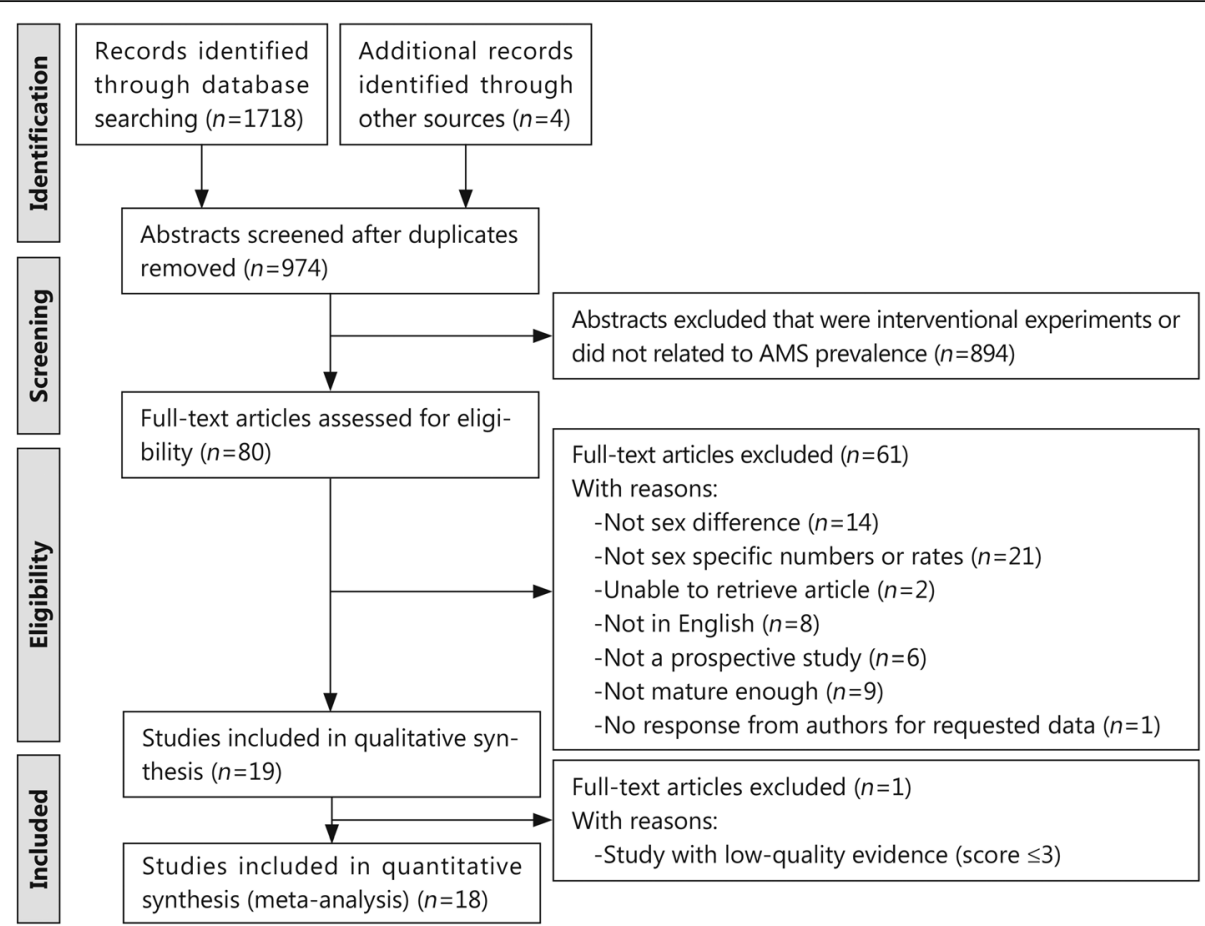

Fig. 1 Flow chart of the study selection process. The flowchart describes the process of searching for and screening of eligible studies on AMS

subgroups stratified by race, but the researchers found no statistically significant differences between Asian and nonAsian populations $(R R=1.27$ vs. $R R=1.16)$, indicating that people of different races have similar susceptibilities to AMS.

Moreover, the results for other subgroups showed that there was no evidence that sex-based differences were affected by age (average age $<40$ years vs. $\geq 40$ years) or LLSS cut-off value (LLSS $\geq 3$ vs. $\geq 4$ ), and all subgroup analysis data are shown in Table 3.

\section{Publication bias}

Publication bias was assessed with meta-funnel plots (Fig. 3), Egger's test and Begg's test. The results showed that there was no evidence of significant publication bias in the combined studies on the basis of Egger's test (bias coefficient $=1.48, P=0.052)$ and Begg's test $(P=0.130)$.

\section{Discussion}

The main purpose of this meta-analysis was to evaluate whether there is a difference between women and men in terms of their susceptibility to AMS using LLSS. After excluding the studies that did not meet the screening criteria, a total of 18 studies were included in this systematic metaanalysis. The results showed that the prevalence of AMS is approximately 1.24 times greater in women than in men, regardless of age or race, however, we could not exclude studies where patients were on acetazolamide. Although no previous systematic evaluation or meta-analysis has shown that AMS has obvious sex-based differences, most of studies are consistent with the results of this meta-analysis (total 15/18); for example, MacInnis et al. [30] reported that the prevalence in women was $45.5 \%$, which was $12.5 \%$ higher than the prevalence in men, indicating that women were more likely than men to suffer from AMS (45.5\% vs $34.0 \%$, $R R=1.62$ ). In contrast, there have been reports that men are more likely than women to suffer from AMS $[9,10]$.

Many mechanisms can explain the relatively high prevalence in women. One hypothesis regarding the pathogenesis is intracranial hypertension $[38,39]$. Two factors contributing to increased intracranial pressure need attention: vascular permeability and fluid retention. Oestrogen is thought to upregulate vascular endothelial growth factor (VEGF) expression [40]. VEGF is responsible for the augmentation of vascular leakage [41], which increases the exudation of tissue fluid and causes intracranial hypertension. Another factor is related to fluid retention. In an early study, the subjects that developed severe AMS displayed water retention within the first $3 \mathrm{~h}$ of altitude exposure; healthy subjects, in contrast, exhibited mild diuresis, or the excretion of urine [42]. The study speculated that this rapid effect is due to an early increase in the anti-diuretic hormone (ADH), which is a hormone that is responsible for water reabsorption by the kidneys. Oestrogen has been shown to lower the threshold for ADH, which causes an increase in fluid retention [43]. This provides another potential mechanism explaining the results of this study.

The second mechanism relates to the concentration of erythropoietin (EPO). After exposure to high altitude, 


\begin{tabular}{|c|c|c|c|}
\hline Study & & & $\%$ \\
\hline ID & & $\mathrm{RR}(95 \% \mathrm{Cl})$ & Weight \\
\hline Murdoch (1995) & $\longrightarrow$ & $2.20(1.17,4.12)$ & 3.03 \\
\hline Ziaee (2003) & & $0.87(0.67,1.14)$ & 7.39 \\
\hline Wagner (2008) & i & $0.82(0.64,1.04)$ & 7.80 \\
\hline Jafarian (2008) & $\rightarrow$ & $1.88(1.06,3.35)$ & 3.43 \\
\hline Mairer (2009) & & $1.17(0.77,1.77)$ & 5.13 \\
\hline Wu (2010) & 1 & $1.42(1.02,1.97)$ & 6.36 \\
\hline Wang (2010) & & $1.01(0.85,1.21)$ & 8.97 \\
\hline Mairer (2010) & & $1.08(0.55,2.15)$ & 2.68 \\
\hline Modesti (2011) & * & $2.91(1.26,6.72)$ & 1.95 \\
\hline Chen (2012) & & $1.09(0.89,1.34)$ & 8.49 \\
\hline Macinnis (2013) & & $1.62(1.25,2.12)$ & 7.41 \\
\hline Mandolesi (2014) & & $1.80(0.62,5.24)$ & 1.29 \\
\hline Hsu (2015) & & $0.63(0.25,1.60)$ & 1.64 \\
\hline Ren (2015) & - & $1.45(1.03,2.05)$ & 6.09 \\
\hline Horiuchi (2016) & & $1.22(0.94,1.59)$ & 7.46 \\
\hline Sánchez-Mascuñano (2017) & & $1.48(1.20,1.82)$ & 8.43 \\
\hline Horiuchi (2018) & 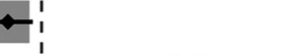 & $1.06(0.94,1.19)$ & 9.92 \\
\hline J. Boos (2018) & - & $2.49(1.23,5.05)$ & 2.55 \\
\hline Overall $\left(I^{2}=66.1 \%, P=0.000\right)$ & & $1.24(1.09,1.41)$ & 100.00 \\
\hline NOTE: Weights are from random effects analysis & & & \\
\hline 0.149 & & 72 & \\
\hline
\end{tabular}

blood components associated with oxygen delivery are affected; the concentration of hemoglobin and count of red blood cells increased sharply [44], which are thought to be advantageous compensations [45]. Testosterone is known to be an androgen that promotes erythropoiesis, which may possibly improve oxygen carrying capacity by increasing EPO levels, conferring an advantage on men at high altitudes [46]. The EPO concentration increases within hours of ascent and stimulates a gradual increase in hemoglobin for men at high altitude; at that point, the human body exhibits a hematological adaptation, reducing

Table 2 Covariates in the meta-regression analysis of AMS studies

\begin{tabular}{lllll}
\hline Heterogeneous factors & Coefficient & Standard error & $t$ & $P$ \\
\hline Race of subjects & -0.0415275 & 0.1847339 & -0.22 & 0.826 \\
Number of subjects & -0.3564554 & 0.1640766 & -2.17 & 0.049 \\
LLSS cut-off value & -0.0223583 & 0.1768234 & -0.13 & 0.901 \\
Average age & 0.0068726 & 0.1774487 & 0.04 & 0.970 \\
Constant & 0.8983218 & 0.4944899 & 1.82 & 0.092 \\
\hline
\end{tabular}

LLSS Lake Louise Scoring System the prevalence of AMS. Furthermore, this is often exploited by male athletes who train at high altitude to increase the oxygen-carrying capacity of their blood to improve sea-level endurance and performance [47].

However, including studied reporting LLS only may limit a large number of studies. Previous researchers have made comparisons between the ESQ-III and the LLSS, they may identify different populations as suffering from AMS [21, 48]. Wanger et al. [20] found that the criterion of LLSS $\geq 3$ with a headache and at least one additional symptom resulted in $63 \%$ of the climbers being diagnosed with AMS, there was a discrepancy in the diagnosis of AMS in about $16 \%$ of the cases which ESQ-III was used. Dellasanta et al. [21] found that using a LLSS score of $\geq 3$ labeled more than twice as many persons as suffering from AMS as were identified with a ESQ-III AMS criterion score of $\geq 0.7$. Therefore, pooled studies using LLSS criterion with studies using other criterion in an analysis is not recommended.

Finally, because of time, energy and other objective constraints, the research has certain limitations. First, as 
Table 3 The heterogeneity of the subgroup analysis of the included AMS studies

\begin{tabular}{|c|c|c|c|c|c|c|}
\hline \multirow[t]{2}{*}{ Subgroup } & \multicolumn{2}{|c|}{ Subjects number } & \multicolumn{2}{|l|}{$\operatorname{AMS}[n(\%)]$} & \multirow[t]{2}{*}{$R R(95 \% \mathrm{Cl})$} & \multirow[t]{2}{*}{$P$} \\
\hline & Women & Men & Women & Men & & \\
\hline All participants & 2639 & 5030 & $1006(38.1)$ & $1722(34.2)$ & $1.24(1.09-1.41)$ & 0.000 \\
\hline \multicolumn{7}{|l|}{ Race } \\
\hline Aisan & 2126 & 3718 & 836(39.3) & $1285(34.6)$ & $1.27(1.10-1.48)$ & 0.000 \\
\hline No-Aisan & 513 & 1312 & 170(33.1) & $437(33.3)$ & $1.16(1.09-1.41)$ & 0.005 \\
\hline \multicolumn{7}{|c|}{ Number of subjects } \\
\hline$<300$ & 344 & 635 & 182(52.9) & $222(35.0)$ & $1.60(1.27-2.00)$ & 0.225 \\
\hline$\geq 300$ & 2295 & 4385 & $824(35.9)$ & $1500(34.2)$ & $1.12(0.98-1.28)$ & 0.001 \\
\hline \multicolumn{7}{|c|}{ LLSS cut-off value } \\
\hline$\geq 3$ & 2176 & 4002 & $848(39.0)$ & 1443(36.1) & $1.25(1.08-1.45)$ & 0.000 \\
\hline$\geq 4$ & 463 & 1028 & 158(34.1) & $279(27.1)$ & $1.27(1.01-1.60)$ & 0.168 \\
\hline \multicolumn{7}{|l|}{ Average age } \\
\hline$<40$ years & 1849 & 3544 & $685(37.0)$ & 1205(34.0) & $1.32(1.02-1.71)$ & 0.000 \\
\hline$\geq 40$ years & 790 & 1486 & $321(40.6)$ & $517(34.8)$ & $1.22(1.04-1.44)$ & 0.013 \\
\hline
\end{tabular}

LLSS Lake Louise Scoring System, AMS acute mountain sickness; $R R$ relative risk, 95\% CI 95\% confidence interval

mentioned in the previous paragraph, there was significant heterogeneity within this meta-analysis. The metaregression and subgroup analysis also indicated the presence of heterogeneity, so it was difficult to avoid bias. Second, some variables within the studies used, including the race of the subjects, the number of subjects who used prophylactic drugs before the experiment and others, could not be standardized. These elements were difficult to resolve in the processing of the studies for analysis. For this reason, some of the heterogeneity may have occurred as a result of these differences among the studies. Third, the inclusion criteria were strict; for example, we selected the LLSS score as the only accepted diagnostic criterion and excluded other systems such as the ESQ-III. In addition, studies that were not prospective were also excluded. The aims of applying these criteria were to reduce the heterogeneity and improve the quality of the studies selected.

\section{Conclusions}

According to this study, women are more likely than men to suffer from AMS ( $R R=1.24,95 \%$ CI 1.09-1.41), but the conspicuous studies' heterogeneity $\left(I^{2}=66.1 \%\right.$, $P=0.000)$ will reduce the reliability of the conclusion. Our analysis provided a direction for future studies of the relationship of sex and the risk of AMS, such as the pathological mechanism and prevention research.

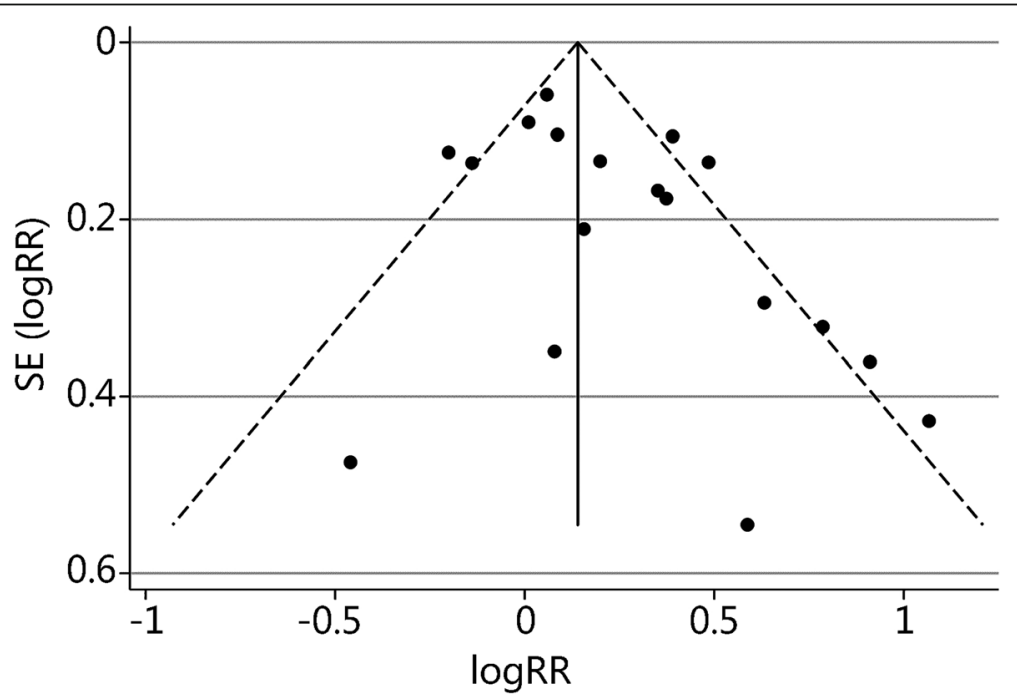

Fig. 3 Funnel plot of the 18 AMS studies to assess publication b.ias. Note the symmetrical distribution of the studies. In addition, all studies were combined and subjected to Egger's test (bias coefficient $=1.48, P=0.052)$ and Begg's test $(P=0.130)$. LogRR: log relative risk; SE (LogRR): standard error of the log relative risk 


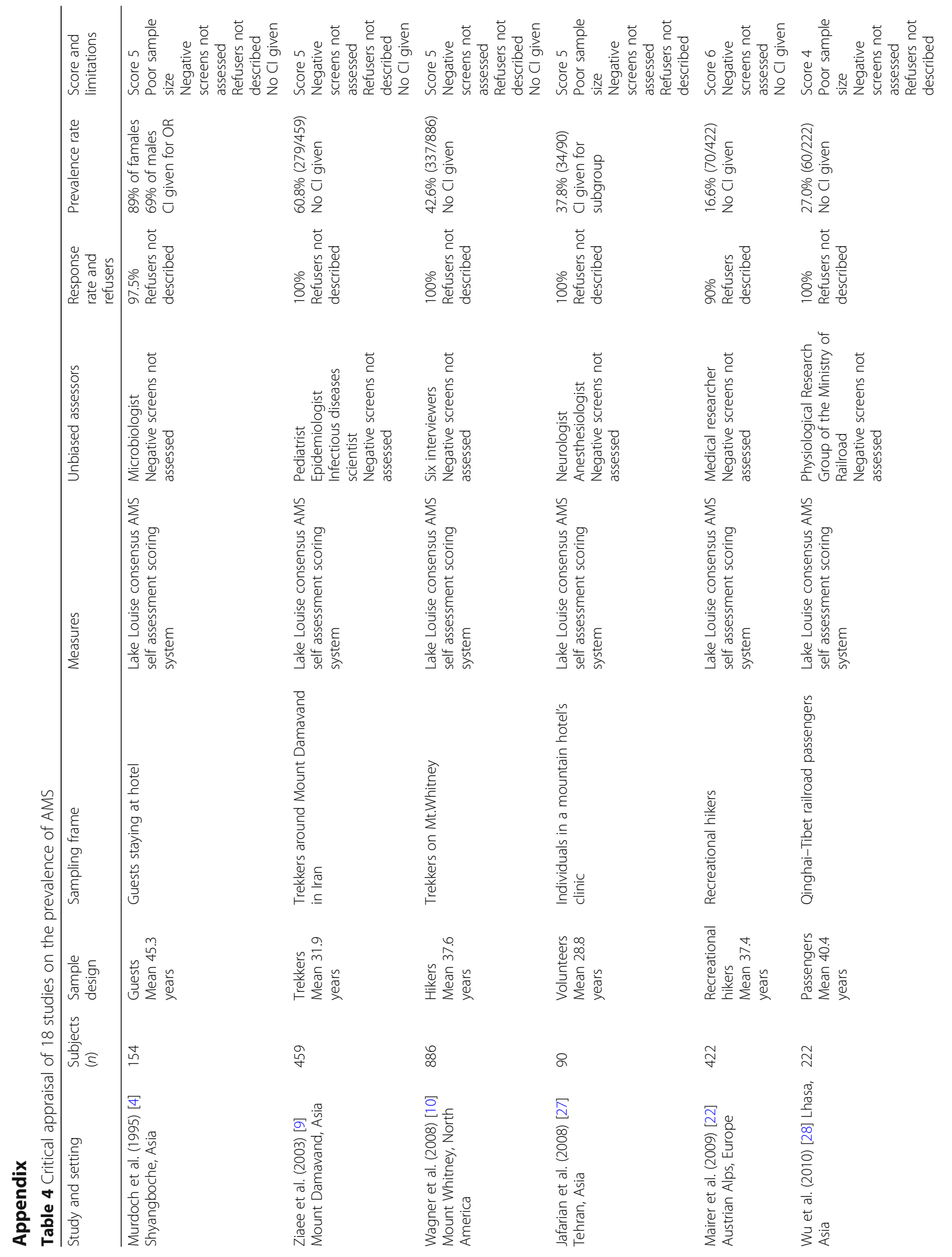




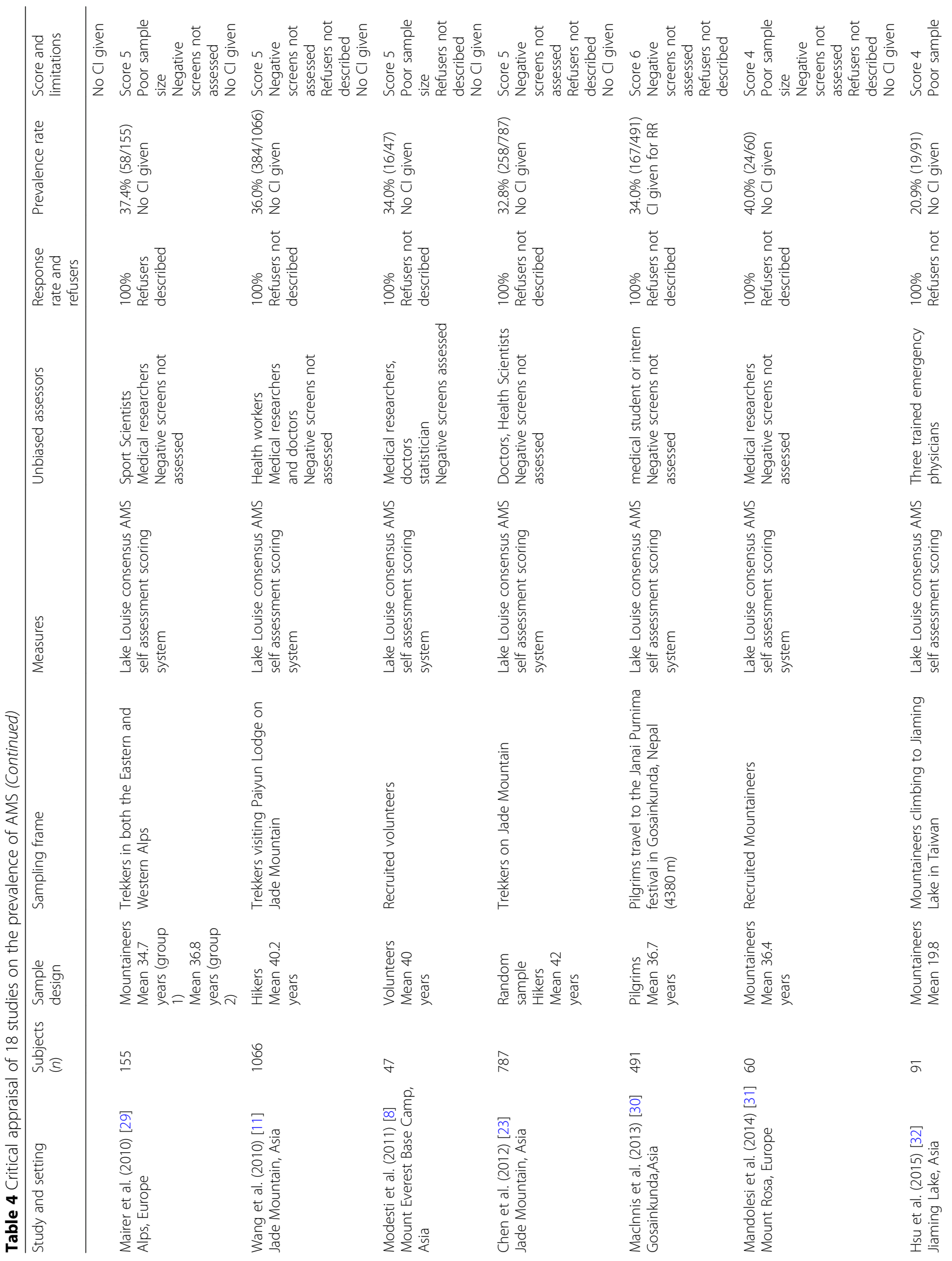




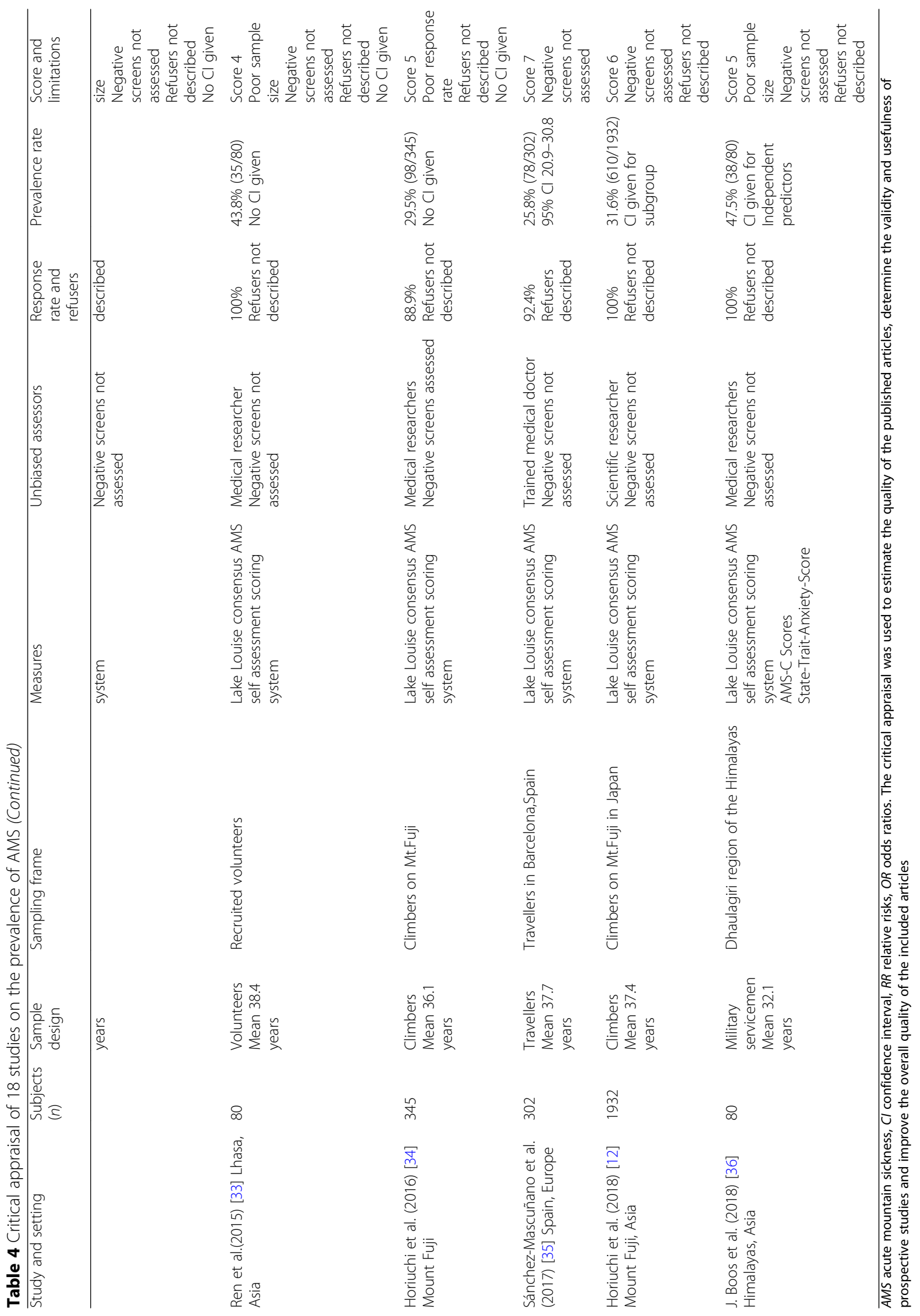




\section{Abbreviations}

ADH: Anti-diuretic hormone; AMS: Acute mountain sickness; 95\% Cl: 95\% confidence interval; EPO: Erythropoietin; ESQ-II: Environmental Symptoms Questionnaire III; LLSS: Lake Louise Scoring System; OR: Odds ratio; $R R$ : Relative ratio; VEGF: Vascular endothelial growth factor

\section{Acknowledgements}

Not applicable.

\section{Authors' contributions}

YPH and JLW collected the data and completed the manuscript. CT, RG, and YC analyzed the data with STATA software. YJL reviewed the results and provided guidelines for the presentation and interpretation. All authors read and approved the final manuscript.

\section{Funding}

This work was supported by the National Natural Science Foundation of China (81571843), the second Tibetan Plateau Scientific Expedition and Research Program (2019QZKK0607), and the Key Special Program of Logistic Scientific Research of PLA (BLJ18J005).

\section{Availability of data and materials}

All data are fully available without restriction.

\section{Ethics approval and consent to participate}

This paper did not use the experimental data from human subjects.

\section{Consent for publication}

Not applicable.

\section{Competing interests}

The authors declare that they have no competing interests.

Received: 19 August 2019 Accepted: 13 November 2019

Published online: 09 December 2019

\section{References}

1. Jin J. Acute mountain sickness. JAMA. 2017;318(18):1840.

2. Hackett PH, Roach RC. High-altitude illness. N Engl J Med. 2001;345(2):107-14.

3. Luo Y, Yang X, Gao Y. Strategies for the prevention of acute mountain sickness and treatment for large groups making a rapid ascent in China. Int J Cardiol. 2013;169(2):97-100.

4. Murdoch DR. Altitude illness among tourists flying to 3740 meters elevation in the Nepal Himalayas. J Travel Med. 1995;2(4):255-6.

5. DiPasquale DM, Strangman GE, Harris NS, Muza SR. Acute mountain sickness symptoms depend on normobaric versus hypobaric hypoxia. Biomed Res Int. 2016;2016:6245609.

6. Wagner DR, Fargo JD, Parker D, Tatsugawa K, Young TA. Variables contributing to acute mountain sickness on the summit of Mt Whitney. Wilderness Environ Med. 2006;17(4):221-8.

7. Beidleman BA, Tighiouart $\mathrm{H}$, Schmid CH, Fulco CS, Muza SR. Predictive models of acute mountain sickness after rapid ascent to various altitudes. Med Sci Sports Exerc. 2013;45(4):792-800.

8. Modesti PA, Rapi S, Paniccia R, Bilo G, Revera M, Agostoni P, et al. Index measured at an intermediate altitude to predict impending acute mountain sickness. Med Sci Sports Exerc. 2011;43(10):1811-8.

9. Ziaee V, Yunesian M, Ahmadinejad Z, Halabchi F, Kordi R, Alizadeh R, et al. Acute mountain sickness in Iranian trekkers around mount Damavand (5671 m) in Iran. Wilderness Environ Med. 2003:14(4):214-9.

10. Wagner DR, D'Zatko K, Tatsugawa K, Murray K, Parker D, Streeper T, et al. Mt. Whitney: determinants of summit success and acute mountain sickness. Med Sci Sports Exerc. 2008;40(10):1820-7.

11. Wang SH, Chen YC, Kao WF, Lin YJ, Chen JC, Chiu TF, et al. Epidemiology of acute mountain sickness on Jade Mountain, Taiwan: an annual prospective observational study. High Alt Med Biol. 2010;11(1):43-9.

12. Horiuchi M, Uno T, Endo J, Handa Y, Hasegawa T. Impact of sleeping altitude on symptoms of acute mountain sickness on Mt. Fuji High Alt Med Biol. 2018;19(2):193-200.

13. Alwerdt J, Patterson AD, Sliwinski MJ. Gender differences in phytoestrogens and the relationship with speed of processing in older adults: a crosssectional analysis of NHANES, 1999-2002. Nutrients. 2019;11(8):1780-92.
14. Puciato D, Mynarski W, Rozpara M, Nawrocka A. Physical activity of Katowice urban area inhabitants with regard to selected physical traits and social factors. Rocz Panstw Zakl Hig. 2018;69(3):273-80.

15. Ding XH, Wang Y, Cui B, Qin J, Zhang JH, Rao RS, et al. Acute mountain sickness is associated with a high ratio of endogenous testosterone to estradiol after high-altitude exposure at 3,700 $\mathrm{m}$ in young Chinese men. Front Physiol. 2019;9:1949.

16. Moher D, Liberati A, Tetzlaff J, Altman DG. Preferred reporting items for systematic reviews and meta-analyses: the PRISMA statement. Int I Surg. 2010:8(5):336-41.

17. Roach RC, Hackett PH, Oelz O, Bartsch P, Luks AM, Maclnnis MJ, et al. The 2018 Lake Louise Acute Mountain sickness score. High Alt Med Biol. 2018. 19(1):4-6.

18. Kobrick JL, Sampson JB. New inventory for the assessment of symptom occurrence and severity at high altitude. Aviat Space Environ Med. 1979; 50(9):925-9.

19. Sampson JB, Kobrick JL. The environmental symptoms questionnaire: revisions and new filed data. Aviat Space Environ Med. 1980;51(9 Pt 1): 872-7.

20. Wagner DR, Teramoto M, Knott JR, Fry JP. Comparison of scoring systems for assessment of acute mountain sickness. High Alt Med Biol. 2012;13(4): 245-51.

21. Dellasanta P, Gaillard S, Loutan L, Kayser B. Comparing questionnaires for the assessment of acute mountain sickness. High Alt Med Biol. 2007;8(3): 184-91.

22. Mairer $\mathrm{K}$, Wille $M$, Bucher T, Burtscher M. Prevalence of acute mountain sickness in the eastern Alps. High Alt Med Biol. 2009;10(3):239-45.

23. Chen HC, Lin WL, Wu JY, Wang SH, Chiu TF, Weng YM, et al. Change in oxygen saturation does not predict acute mountain sickness on Jade Mountain. Wilderness Environ Med. 2012;23(2):122-7.

24. Loney PL, Chambers LW, Bennett KJ, Roberts JG, Stratford PW. Critical appraisal of the health research literature: prevalence or incidence of a health problem. Chronic Dis Can. 1998;19(4):170-6.

25. Gallis JA, Turner EL. The risks of odds ratios: relative risks are more naturally understood. BJOG. 2019. https://doi.org/10.1111/1471-0528.15507.

26. Moher D, Liberati A, Tetzlaff J, Altman DG. Preferred reporting items for systematic reviews and meta-analyses: the PRISMA statement. PLoS Med. 2009:6(7):e1000097.

27. Jafarian S. Respiratory rate within the first hour of ascent predicts subsequent acute mountain sickness severity. Arch Iran Med. 2008;11(2):152-6.

28. Wu TY, Ding SQ, Zhang SL, Duan JQ, Li BY, Zhan ZY, et al. Altitude illness in Qinghai-Tibet railroad passengers. High Alt Med Biol. 2010;11(3):189-98.

29. Mairer K, Wille M, Burtscher M. The prevalence of and risk factors for acute mountain sickness in the eastern and Western Alps. High Alt Med Biol. 2010;11(4):343-8.

30. Maclnnis MJ, Carter EA, Freeman MG, Pandit BP, Siwakoti A, Subedi A, et al. A prospective epidemiological study of acute mountain sickness in Nepalese pilgrims ascending to high altitude (4380 m). PLoS One. 2013; 8(10):e75644.

31. Mandolesi G, Avancini G, Bartesaghi M, Bernardi E, Pomidori L, Cogo A. Long-term monitoring of oxygen saturation at altitude can be useful in predicting the subsequent development of moderate-to-severe acute mountain sickness. Wilderness Environ Med. 2014:25(4):384-91.

32. Hsu TY, Weng YM, Chiu YH, Li WC, Chen PY, Wang SH, et al. Rate of ascent and acute mountain sickness at high altitude. Clin J Sport Med. 2015;25(2): 95-104.

33. Ren XW, Zhang QY, Wang H, Hong H, Qiao HY, Man CY, et al. The relationship between baseline exhaled nitric oxide levels and acute mountain sickness. Am J Med Sci. 2015;349(6):467-71.

34. Horiuchi M, Endo J, Akatsuka S, Uno T, Jones TE. Prevalence of acute mountain sickness on Mount Fuji: A pilot study. J Travel Med. 2016;23(4):1-5.

35. Sanchez-Mascunano A, Masuet-Aumatell C, Morchon-Ramos S, Ramon JM Relationship of altitude mountain sickness and smoking: a Catalan traveller's cohort study. BMJ Open. 2017:7(9):e017058.

36. Boos CJ, Bass M, O'Hara JP, Vincent E, Mellor A, Sevier L, et al. The relationship between anxiety and acute mountain sickness. PLoS One. 2018;13(6):e0197147.

37. Pesce C, Leal C, Pinto H, Gonzalez G, Maggiorini M, Schneider M, et al. Determinants of acute mountain sickness and success on Mount Aconcagua (6962 m). High Alt Med Biol. 2005;6(2):158-66.

38. Singh I, Khanna PK, Srivastava MC, Lal M, Roy SB, Subramanyam CS. Acute mountain sickness. N Engl J Med. 1969;280(4):175-84. 
39. Lawley JS, Alperin N, Bagci AM, Lee SH, Mullins PG, Oliver SJ, et al. Normobaric hypoxia and symptoms of acute mountain sickness: elevated brain volume and intracranial hypertension. Ann Neurol. 2014;75(6):890-8.

40. Tang $H$, Zhang W, Zhu Y, Zhang X, Wang R. Estrogen decreases vascular damage induced by chronic hypoperfusion through upregulating VEGF expression (article in China). J South Med Univ. 2015;35(11):1552-6.

41. Schoch HJ, Fischer S, Marti HH. Hypoxia-induced vascular endothelial growth factor expression causes vascular leakage in the brain. Brain. 2002; 125(Pt 11):2549-57.

42. Loeppky JA, Icenogle MV, Maes D, Riboni K, Hinghofer-Szalkay H, Roach RC. Early fluid retention and severe acute mountain sickness. J Appl Physiol (1985). 2005;98(2):591-7.

43. Stachenfeld NS, Silva C, Keefe DL, Kokoszka CA, Nadel ER. Effects of oral contraceptives on body fluid regulation. J Appl Physiol (1985). 1999;87(3): 1016-25.

44. Ding XH, Zhang JH, Cui B, Huang L. Relationship between excessive erythrocytosis and acute mountain sickness: a field study. Mil Med Res. 2014;1:18

45. Frappell PB, Leon-Velarde F, Rivera-Ch M. Oxygen transport at high altitude--an integrated perspective. Introduction Respir Physiol Neurobiol. 2007;158(2-3):115-20.

46. Shahani S, Braga-Basaria M, Maggio M, Basaria S. Androgens and erythropoiesis: past and present. J Endocrinol Investig. 2009;32(8):704-16.

47. Ploszczyca K, Langfort J, Czuba M. The effects of altitude training on erythropoietic response and hematological variables in adult athletes: a narrative review. Front Physiol. 2018;9:375

48. Maggiorini M, Muller A, Hofstetter D, Bartsch P, Oelz O. Assessment of acute mountain sickness by different score protocols in the Swiss Alps. Aviat Space Environ Med. 1998;69(12):1186-92.

Ready to submit your research? Choose BMC and benefit from:

- fast, convenient online submission

- thorough peer review by experienced researchers in your field

- rapid publication on acceptance

- support for research data, including large and complex data types

- gold Open Access which fosters wider collaboration and increased citations

- maximum visibility for your research: over $100 \mathrm{M}$ website views per year

At $\mathrm{BMC}$, research is always in progress.

Learn more biomedcentral.com/submissions 